\title{
Effect of Levodopa (L-Dopa) on Serum Growth Hormone in Ghildren with Short Stature
}

\author{
Zaven H. Chakmakjtan ${ }^{[16]}$, James F. Marks, and Chester W. Fink \\ Weinberger Endocrine Laboratory, Departments of Medicine and Pathology, Baylor University Medical Center, and Department of \\ Pediatrics, University of Texas Southwestern Medical School, Dallas, Texas, USA
}

\begin{abstract}
Extract
The diagnostic usefulness of levodopa (L-dopa) as a provocative agent for stimulating growth hormone (GH) release was investigated in 22 children with short stature. Complete endocrine evaluation showed 17 to have normal pituitary function (group $I$ ) and 5 GH deficiency (group II). Serial serum GH measurements were made under basal conditions after arginine infusion, insulin hypoglycemia, and single dose oral administration of L-dopa (100-500 mg). Mean GH levels after L-dopa in group I were, in nanograms per milliliter: $0 \mathrm{~min}, 4.8 ; 30 \mathrm{~min}, 7.0 ; 60 \mathrm{~min}, 16.5 ; 90 \mathrm{~min}, 12.6 ; 120 \mathrm{~min}, 8.4$; $150 \mathrm{~min}, 3.2 ; 180 \mathrm{~min}, 1.9$. A significant $\mathrm{GH}$ rise was seen in 15 of 17 children, but a normal response as defined in the text was observed in 13 of 17. Peak GH response occurred between 30 and 120 min. Mean peak GH responses to L-dopa were 21.3, arginine 25.2, and insulin 21.3. The two nonresponders to L-dopa in group $I$ showed normal GH response to insulin. The response to arginine was normal in one and partial in the other. Group II subjects showed no GH response to the three agents. Side effects to L-dopa were minimal and usually limited to temporary nausea. By virtue of its ready availability and simplicity of administration, the L-dopa test appears to bc a good means of determining $\mathrm{GH}$ reserve.
\end{abstract}

\section{Speculation}

L-Dopa administered as a single oral dose seems to be a simple and valid agent for evaluation of pituitary GH reserve.

\section{Introduction}

Recently, Boyd et al. [2] reported an acute elevation in immunoreactive serum growth hormone (GH) in patients with Parkinson's disease after administration of x-dopa. One of us [3] has also demonstrated that a single dose of L-dopa, when given orally, can cause a significant rise in peripheral serum GH in healthy adult volunteers. In view of these results, we wanted to investigate the diagnostic usefulness of oral L-dopa as a provocative agent for stimulating $\mathrm{GH}$ release in children with short stature. The present report shows our ex- perience with this agent. Also comparison is made with insulin-induced hypoglycemia and arginine infusion both of which have become the established provocative tests for $\mathrm{GH}$ release $[4,5,7]$.

\section{Materials and Methods}

Twenty-two patients, aged 5-17 years, were studied. Seventeen were considered to have constitutional short stature (group I) on the basis of history, physical examination, bone age x-rays, and complete pituitary endocrine evaluation. Five were GH deficient (group II) 
based on above criteria and lack of $\mathrm{GH}$ response to insulin hypoglycemia and arginine infusion.

On the morning of the study, breakfast was withheld, an informed consent was obtained, and a 19-gauge scalp vein needle was inserted into a peripheral vein. The system was kept open with heparinized saline. After a 30-min rest, a single oral dose of L-dopa [12] was given (100-500 mg), depending on the weight of each subject. Blood samples were obtained just before administration of L-dopa and then at 30-min intervals for a total of $180 \mathrm{~min}$. After similar preparation, GH responses had been previously investigated by the arginine infusion (17 patients) and insulin-induced hypoglycemia (20 patients). In 11 patients, sequential arginine and insulin tests were performed on the same day according to the recommendation of Penny et al. [8], except that insulin was given $90-120 \mathrm{~min}$ after the start of arginine. All male control subjects were primed with $2.5 \mathrm{mg}$ diethylstilbestrol twice daily for $48 \mathrm{hr}$. The arginine was infused over $30 \mathrm{~min}(0.5 \mathrm{~g} / \mathrm{kg}$ or $30 \mathrm{~g}$ maximum). Crystalline insulin was given intravenously $(0.1-0.12$ $\mathrm{U} / \mathrm{kg}$ ). Blood samples were collected every $30 \mathrm{~min}$ for at least $90 \mathrm{~min}$. An elevation of $\mathrm{GH}$ to at least $7 \mathrm{ng} / \mathrm{ml}$ or an increment of $5 \mathrm{ng} / \mathrm{ml}$ over base line was considered to be a normal GH response [4, 7, 8]. Subjects who showed significant GH elevations over base line, but did not meet the preceding criteria, were classified as partial responders.

Serum GH [13] was measured by the double antibody radioimmunoassay method [1]. The lower limit of the sensitivity of this assay is $0.5 \mathrm{ng} / \mathrm{ml}$ serum. All samples of each test were run in the same assay and in duplicate.

\section{Results}

The acute effect of a single oral dose of L-dopa on serum GH in group $I$ and $I I$ subjects is shown in Table I. Also the mean \pm sEM GH levels throughout the L-dopa test in both groups is plotted graphically in Figure 1. A significant rise attributable to L-dopa was observed in 15 out of the 17 subjects in group $I$, but a normal response as previously defined was seen only in 13. The peak GH elevation occurred between 30 and $120 \mathrm{~min}$. Almost all responders showed a significant in-

Table $I$. Serum growth hormone (GH) response to L-dopa in 17 children with constitutional short stature (group I) and 5 children with GH deficiency (group II)

\begin{tabular}{|c|c|c|c|c|c|c|c|c|c|c|}
\hline \multirow{2}{*}{ Subjects } & \multirow{2}{*}{ Age, yrs } & \multirow{2}{*}{ Sex } & \multirow{2}{*}{ I-Dopa dose, mg } & \multicolumn{7}{|c|}{$\mathrm{GH}, \mathrm{ng} / \mathrm{ml}$} \\
\hline & & & & $0 \mathrm{~min}$ & $30 \mathrm{~min}$ & $60 \mathrm{~min}$ & $90 \min$ & $120 \mathrm{~min}$ & $150 \mathrm{~min}$ & $180 \mathrm{~min}$ \\
\hline \multicolumn{11}{|l|}{ Group I } \\
\hline$R M$ & 15 & $\mathbf{M}$ & 250 & 13.4 & 2.2 & 27.2 & 32.0 & 6.4 & 2.6 & 1.2 \\
\hline$W S$ & $124 / 12$ & $\mathrm{M}$ & 250 & 21.0 & 31.0 & 47.0 & 31.0 & 10.4 & 2.2 & 1.6 \\
\hline$D H$ & $79 / 12$ & $\mathrm{M}$ & 250 & 2.4 & 6.0 & 53.0 & 21.0 & 8.4 & 11.6 & 3.6 \\
\hline$A H$ & $109 / 12$ & $\mathbf{M}$ & 250 & 1.8 & 7.0 & 5.2 & 12.2 & 3.6 & 2.0 & 2.4 \\
\hline$J H$ & 15 & $\mathbf{M}$ & 250 & 2.6 & 5.8 & 5.6 & 3.8 & 4.4 & 4.0 & 3.0 \\
\hline$T W$ & 12 & $\mathrm{M}$ & 250 & 2.6 & 1.2 & 11.0 & 27.0 & 40.0 & 2.8 & 1.4 \\
\hline$D P$ & 12 & $F$ & 250 & 0.6 & 1.8 & 1.4 & 1.0 & 0.4 & 0.4 & 0.4 \\
\hline$K L$ & 9 & $\mathrm{M}$ & 100 & 1.0 & 1.6 & 8.6 & 1.8 & 1.0 & 0.8 & 0.8 \\
\hline$P D$ & $56 / 12$ & $\mathbf{M}$ & 100 & 2.4 & 2.8 & 7.0 & 8.2 & 9.4 & 2.0 & 1.6 \\
\hline$D S$ & 8 & $\mathbf{M}$ & 100 & 6.4 & 2.6 & 2.2 & 11.4 & 3.6 & 1.0 & 1.0 \\
\hline$L G$ & 15 & $\mathrm{M}$ & 250 & 2.8 & 9.8 & 30.4 & 13.6 & 7.6 & 3.4 & 1.4 \\
\hline$D W$ & 5 & $\mathrm{M}$ & 100 & 6.4 & 5.2 & 32.5 & 9.0 & 13.4 & 5.2 & 2.4 \\
\hline$R E$ & 15 & $\mathbf{M}$ & 250 & 1.4 & 1.6 & 0.6 & 5.2 & 2.8 & 1.4 & 0.8 \\
\hline$R J$ & 7 & $\mathbf{M}$ & 100 & 9.2 & 33.5 & & 23.5 & 20.0 & 8.0 & 4.6 \\
\hline$A B$ & 15 & $\mathrm{M}$ & 250 & 3.2 & 2.6 & 1.8 & 7.0 & 7.4 & 2.6 & 1.8 \\
\hline$A J$ & $56 / 12$ & $\mathrm{M}$ & 100 & 3.2 & 3.4 & 1.8 & 1.6 & 1.0 & & \\
\hline$W E$ & 5 & M & 100 & 2.0 & 1.0 & 29.4 & 5.4 & 2.2 & 1.6 & 3.0 \\
\hline Mean & & & & 4.8 & 7.0 & 16.5 & 12.6 & 8.4 & 3.2 & 1.9 \\
\hline $\pm S E M$ & & & & 1.3 & 2.4 & 4.3 & 2.5 & 2.3 & 0.7 & 0.3 \\
\hline \multicolumn{11}{|l|}{ Group II } \\
\hline$T T$ & 10 & $\mathrm{M}$ & 100 & 1.6 & 1.2 & 1.0 & 1.4 & 0.8 & 1.4 & 1.4 \\
\hline$M B$ & 11 & $\mathbf{M}$ & 100 & 1.8 & 2.0 & 2.0 & 1.6 & 1.6 & 2.2 & 1.8 \\
\hline$T B$ & 10 & $\mathbf{M}$ & 250 & 1.0 & 0.6 & 1.0 & 3.2 & 1.8 & 0.4 & 0.2 \\
\hline$P C$ & 17 & $\mathbf{M}$ & 500 & 1.8 & 1.6 & 1.4 & 1.6 & 1.6 & 2.0 & 1.6 \\
\hline$W D$ & 14 & $\mathrm{M}$ & 250 & 1.8 & 2.8 & 2.0 & 2.0 & 2.2 & 2.6 & 2.2 \\
\hline Mean & & & & 1.6 & 1.6 & 1.5 & 2.0 & 1.6 & 1.7 & 1.4 \\
\hline 土SEM & & & & 0.2 & 0.4 & 0.2 & 0.3 & 0.2 & 0.4 & 0.3 \\
\hline
\end{tabular}




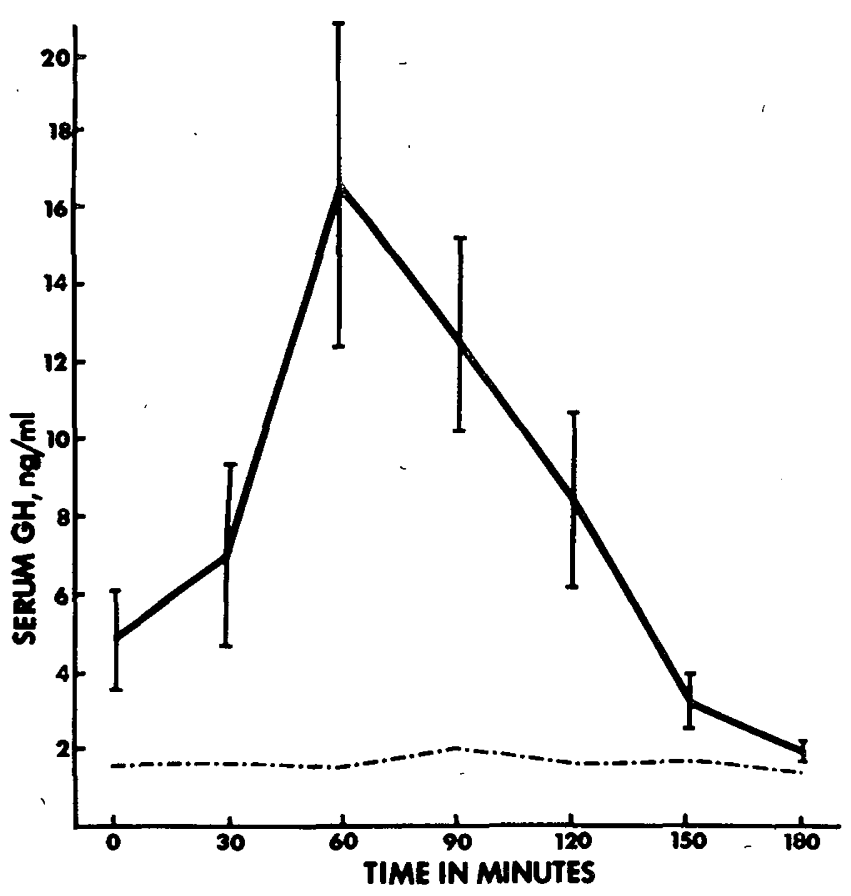

Fig. 1. Mean \pm SEM serum growth hormone (GH) response to $\mathrm{x}$-dopa in 17 children with constitutional short stature $(\longrightarrow)$ and 5 with GH deficiency (-•-•-).

crement by $60 \mathrm{~min}$ except for control subjects $D S$ and $A B$, in whom the earliest response was at $90 \mathrm{~min}$. The finding of elevated base-line $\mathrm{GH}$ values $(>5 \mathrm{ng} / \mathrm{ml})$ in five group $I$ children probably reflects $\mathrm{GH}$ release secondary to stress of venipuncture. Table II compares the individual peak $\mathrm{GH}$ responses with each of the three provocative agents in group $I$ children. The mean \pm SEM peak response to L-dopa was GH $21.3 \pm 4.0$, arginine $25.2 \pm 4.1$, and insulin $21.3 \pm 3.3$. Patient $J H$, who showed a partial $\mathrm{GH}$ response, and $A J$, who showed no response to L-dopa, had each responded normally to arginine and insulin. Patients $R E$, who also showed a partial GH response, and $D P$, who showed no response to L-dopa, had normal responses to insulin but partial responses to arginine. None of the subjects in group $I I$ showed GH response to L-dopa, arginine, and insulin. The only side effects that were noticed following $\mathrm{x}$-dopa were occasional temporary nausea in some and urinary frequency in others.

\section{Discussion}

The recent demonstration of consistent serum GH elevation after single dose, orally administered L-dopa in patients with Parkinson's disease [2] and adult healthy volunteers [3] prompted us to investigate the feasibility of the diagnostic usefulness of L-dopa in children with short stature. Our results show that L-dopa stimulates the secretion of GH release in the majority of children studied. The exact mechanism of its action is still unexplained. It is speculated that L-dopa which effectively crosses the blood-brain barrier acts by increasing dopamine and/or norepinephrine levels in the median eminence and hypothalamus, thereby mediating the secretion of GH-releasing factor $[2,11]$. It is interesting to note that this phenomenon seems to be limited to GH. Under similar circumstances, L-dopa does not seem to promote release of other anterior pituitary hormones [3]. We did not see any effect on serum thyroid-stimulating hormone in four children (group I) who had responded to L-dopa with GH elevations.

The lack of consistent GH elevation in all group $I$ subjects may limit the use of L-dopa as the only diagnostic test in evaluation of GH secretion in children with short stature. However, its ready availability and ease of administration makes it more advantageous than the other tests so far utilized.

In this study, GH responses as early as $30 \mathrm{~min}$ or as late as $90 \mathrm{~min}$ after L-dopa administration were observed. Therefore, blood samples should be collected up to $90 \mathrm{~min}$. Additional sampling does not seem to be necessary.

Since this drug is administered orally, the rate of absorption from the gut, the quantity entering the

Table $I X$. Comparison of the individual peak GH responses to each of the three provocative agents in group $I$ children

\begin{tabular}{lrcr}
\hline \multirow{2}{*}{ Subjects } & \multicolumn{3}{c}{ Maximal response to } \\
\cline { 2 - 4 } & I-Dopa & Arginine & Insulin \\
\hline$R M$ & 32.0 & 18.4 & 36.4 \\
$W S$ & 47.0 & 18.6 & 28.4 \\
$D H$ & 53.0 & 40.0 & 48.0 \\
$A H$ & 12.2 & 58.4 & 31.0 \\
$J H$ & 5.8 & 40.0 & 29.4 \\
$T W$ & 40.0 & 14.0 & 25.5 \\
$D P$ & 1.8 & 6.2 & 5.6 \\
$K L$ & 8.6 & 40.0 & 7.4 \\
$P D$ & 9.4 & & 17.0 \\
$D S$ & 11.4 & 22.4 & 11.0 \\
$L G$ & 30.4 & 25.0 & 9.4 \\
$D W$ & 32.5 & 14.6 & \\
$R E$ & 5.2 & 4.4 & 8.4 \\
$R J$ & 33.5 & & 42.0 \\
$A B$ & 7.4 & & 7.8 \\
$A J$ & 3.4 & 37.0 & 18.0 \\
$W E$ & 29.4 & 14.4 & 16.6 \\
Mean & 21.3 & 25.2 & 21.3 \\
\pm SEM & 4.0 & 4.1 & 3.3 \\
\hline
\end{tabular}

